\title{
Editorial: Special Issue with Research Topic
}

\author{
James Weinberg ${ }^{1 *}$, Ben Seyd ${ }^{2}$, Jennifer R. Gaskell ${ }^{3}$, Joseph A. Hamm ${ }^{4}$ and Sonja Zmerli ${ }^{5}$ \\ ${ }^{1}$ Department of Politics and International Relations, The University of Sheffield, Sheffield, United Kingdom, ${ }^{2}$ School of Politics and \\ International Relations, University of Kent, Canterbury, United Kingdom, ${ }^{3}$ Department of Politics and International Relations, \\ University of Southampton, Southampton, United Kingdom, ${ }^{4}$ School of Criminal Justice, Michigan State University, East Lansing, \\ MI, United States, ${ }^{5}$ Sciences Po Grenoble, Université Grenoble Alpes, Grenoble, France
}

Keywords: trust, distrust, mistrust, democracy, theory and measurement

\section{Editorial on the Research Topic}

\section{Special Issue with Research Topic}

Long before the populist tide of the last decade, exemplified by the election of leaders like Donald Trump, Narendra Modi and Boris Johnson, and the economic shock-waves from the 2007-8 global financial crash, academics and political commentators alike were concerned with the gradual yet steady decline of political trust in many established democracies. As a concept and as political capital, trust is at the heart of commentaries on social cohesion as well as studies of economic growth and financial development, devolution and decision-making, political stability and government performance, and even subjective well-being. Indeed, political trust is recognized as one of the most valuable lubricants for societal and international cooperation, political legitimacy, and peace available to democracies. Its importance has been thrust centre-stage over the past 18 months as the coronavirus pandemic has forced us to confront the need for cooperation between citizens and governments, and in turn the vital role of trust in facilitating such cooperative links.

At the same time, there is much we do not yet know about this important element of social and political life. The purpose of this Research Topic is to bring together a collection of works pushing the boundaries of thought on political trust. This introductory essay outlines the contributions and the ways in which they help us better understand trust. We conclude by identifying unanswered questions in the hopes of stimulating new research.

The eight Original Research articles in this collection speak to three major themes relating to political trust:

1. How should we conceive of trust and distrust in politics, and are there any other conditions that need identification and measurement?

2. What are the key factors contributing to citizens' trust judgments?

3. What are the consequences of trust for effective governance?

\section{THE CONDITIONS OF TRUST}

Across academic disciplines, there is no shortage of conceptual discussions on the topic of trust. Where exploration in social science has been less extensive, however, is in probing whether conceptual distinctions receive empirical validation. One area where this would be particularly welcome concerns distinctions between "trust", its opposite, "distrust", and a third condition, "mistrust", which is often held to characterise a questioning or cautious approach by citizens. Surveys tell us that few citizens are fully trustful, while rather more are distrustful. This leaves many citizens likely to fall into the mistrustful camp. In their contribution to this Research Topic, Bunting et al. 
field indicators tapping each state of trust, and empirically show distinctions in the conditions of trust, mistrust and distrust among citizens. While it is unsurprising to find clear distinctions between trust and distrust in citizens' minds, Bunting and her colleagues show that a state of scepticism about politicians can be empirically distinguished from feeling either trustful or distrustful. These results have important implications for the way trust is measured and for analyses of its effects across a range of democratic and political outcomes.

\section{THE FACTORS OF TRUST}

Our understanding of trust-and ability to identify initiatives that might boost trust-is critically dependent on being able to identify its causes, and this Research Topic contributes to that task. The articles contained in it focus in particular on three main issues: the breadth of factors that affect trust; explaining variations in trust between different national political systems; and how the levels and stimulants of trust vary between different spatial units and tiers of government.

\section{Factors Affecting Trust}

There is an extensive literature on the causes of trust (see Zmerli et al., 2017; Uslaner, 2018). Yet while these studies have enhanced our understanding of trust's antecedents, there remains considerable room for studies which consider how trust is shaped by a range of factors, and how trust may also be shaped by particular attitudes and perceptions that go beyond the "usual suspects" explored in the literature.

In their study, Torcal and Christmann explore and explain the evolution of trust in Spain over a 20-year period from 1997. Unsurprisingly, they show that people's trust in government took a substantial hit after the financial crash in 2008. Yet levels of trust did not rebound once economic recovery took place, largely because of negative judgements about politicians' responsiveness and integrity. By bringing together citizens' judgements about the economy, political responsiveness and corruption, the authors make clear how trust is shaped by a variety of evaluations.

In his article, Greenwood-Hau leverages System Justification Theory to argue that evaluations of the causes of social inequality may be an important determinant of political trust, conceptualized here as an evaluation of government. Despite mixed results, the paper provides some evidence of the hypothesized relations in new data collected in the UK.

\section{Variations Across Political Systems}

The analysis provided by Mauk finds that the democratic quality of a country does not directly affect trust. Rather, it shapes citizens' evaluations of democratic performance-moderated by levels of education, political interest and democratic aspirations-which then shape levels of trust. Mauk's analysis therefore provides an important unpicking of the relationship between the democratic quality of a country, on the one hand, and levels of trust among its citizens, on the other.
The article by Schnaudt et al. points to rather different effects of democratic conditions on trust judgements. These authors examine the impact on trust of evaluations of justice. While the link between outcome evaluations like trust and legitimacy and appraisals of decision or system fairness has long been established (eg. Thibaut and Walker, 1975), an open question remains whether such links vary between contexts. The authors' crossnational analysis points to important conditionalities in these links, with evaluations of justice more strongly linked to trust in countries where levels of fairness are lower than in more equitable national contexts.

\section{The Impact of Territory and Multi-Level Systems}

One area that has gained more scholarly attention recently has been the geography of attitudes, an issue taken up by two articles in this Research Topic that explore the territorial distribution and stimulants of trust. Picking up on recent research on the spatial distribution of electoral support for populist parties, McKay et al. consider how patterns of trust vary across space and how these distributions are affected by different stimulants. McKay and colleagues challenge a received wisdom in social science that draws causal chains from economic inequality to political distrust to populism (Rodriguez-Pose, 2018). In contrast, they highlight the added importance of social grievances as a fillip to trust judgements across different loci. In particular, they find that people outside of cities may lack trust because they feel socially marginalised, whilst people in deprived communities are likely to lack trust because they feel both economically and socially neglected.

The impact of territory on trust is also addressed in Steenvoorden and van der Meer's article. The territorial element here concerns citizens' appraisals of the different tiers of government found in multilevel political systems. Using data from the Netherlands, Steenvoorden and van der Meer find that people's trust in local government is shaped as much by their evaluations of national government as by their evaluations of performance at the local level. These results contribute important new evidence to our understanding of the ways in which people's trust in one institution is shaped by their evaluations of other-often more high profile-institutions (PytlikZillig et al., 2016). Steenvoorden and van der Meer's study also contributes valuable new evidence to our understanding of the conditionalities of trust; that different individuals often form trust judgements in different ways. In particular, the study shows that trust in local government among politically sophisticated individuals is more strongly shaped by local performance evaluations than is trust among less sophisticated individuals.

\section{TRUST AND EFFECTIVE GOVERNANCE}

As proposed by Almond and Verba (1963), and noted at the start of this article, trust has long been seen as a vital element in the effective functioning of social, economic and political systems. Yet almost 60 years on from the Civic Culture study, research on 
the effects of political trust has lagged behind descriptive and explanatory research. While important studies on the impact of trust on effective governance have appeared in recent years (eg. Hetherington, 2005) — and have been magnified over the past year or so by the role of trust during the coronavirus pandemic-less attention has been focused on why trust might shape people's behaviour in important pro-social or collective ways. This issue is taken up by Fairbrother et al. in their analysis of the effect of trust on people's support for future-oriented policies on climate change and public debt. Departing from the empirically validated "political trust as a heuristic" hypothesis (Rudolph, 2017), the authors demonstrate for a diverse set of countries that politically trustful citizens also tend to be more confident in the effectiveness of proposed future-oriented policies and more willing to "sacrifice" own resources for the wellbeing of future generations, all of which, in turn, strengthen policy support. At the same time, their findings debunk economists' assertion that trust in the problem-solving capacities of political institutions and actors may attenuate citizens' willingness to invest in future generations.

\section{GOING FORWARD ON TRUST}

Individually and collectively, the articles gathered in this Research Topic make important contributions to our understanding of the nature, causes and consequences of political trust. Yet there remain important questions around this vital concept, and we conclude by briefly highlighting areas we feel researchers might profitably target in future studies. While each of the articles in this Research Topic treats trust as an evaluative response, we (as political scientists) are sensitive to other treatments of trust, notably psychologists' focus on cognitive and affective stimuli and sociologists' focus on basic orientations and socialisation processes. Trust is best understood through a mixture of

\section{REFERENCES}

Almond, G. A., and Verba, S. (1963). The Civic Culture: Political Attitudes and Democracy in Five Nations. Princeton NJ: Princeton University Press.

Hetherington, M. J. (2005). Why Trust Matters: Declining Political Trust and the Demise of American Liberalism. Princeton, NJ: Princeton University Press.

Intawan, C., and Nicholson, S. P. (2018). My Trust in Government Is Implicit: Automatic Trust in Government and System Support. J. Polit. 80 (2), 601-614. doi:10.1086/694785

PytlikZillig, L. M., Hamm, J. A., Shockley, E., Herian, M. N., Neal, T. M. S., Kimbrough, C. D., et al. (2016). The Dimensionality of Trust-Relevant Constructs in Four Institutional Domains: Results from Confirmatory Factor Analyses. J. Trust Res. 6 (2), 111-150. doi:10.1080/ 21515581.2016.1151359

Rodríguez-Pose, A. (2018). The Revenge of the Places that Don't Matter (And what to Do about it). Camb. J. Reg. Econ. Soc. 11, 189-209. doi:10.1093/cjres/rsx024

Rudolph, T. (2017). "Political Trust as a Heuristic," in Handbook on Political Trust. Editors S. Zmerli and T. W. G. van der Meer (Cheltenham, UK: Edward Elgar), $197-211$.

Thibaut, J. W., and Walker, L. (1975). Procedural Justice: A Psychological Analysis. Hillsdale, NJ: L. Erlbaum Associates. perspectives and approaches, and we would welcome more cross-fertilisation of such approaches.

Linked to issues around the nature of trust are questions around its measurement. Social scientists-and political scientists in particular-have often uncritically accepted conventional survey-based measures of trust, and shown a lack of curiosity about alternative ways of measuring trust. The reliance on survey measures of trust would not matter so much if alternative measures identified broadly similar distributions. Yet in some cases they do not (for an example, see Intawan and Nicholson, 2018). We would like to see researchers take measurement more seriously and to invest more resources in different ways of measuring trust. Moreover, any such initiatives need to incorporate indicators of mistrust, as well as the more usual indicators of trust and distrust.

Finally, the unwanted presence of the coronavirus has forced researchers to examine the effects of trust on important forms of collective behavior and social cooperation. Yet if levels of trust in many countries have declined, we surely need to know more about the potential consequences of low and declining trust. Further research in this area is vital if we are to better understand the areas in which political trust may-and may not-be important for effective democracy and governance.

\section{AUTHOR CONTRIBUTIONS}

This Research Topic on Political Trust was initially proposed and set up by JW. All of the editors worked collaboratively to decide which papers were accepted or rejected, and each manuscript was subject to review by the panel of editors as well as peer reviewers. This editorial introduction was led by BS. All of the editorial team contributed their thoughts and revisions to help craft the published document.

Uslaner, E. M. (2018). The Oxford Handbook of Social and Political Trust. Oxford: Oxford University Press.

Zmerli, S., and van der Meer, T. W. G. (2017). Handbook on Political Trust. Cheltenham, UK: Edward Elgar.

Conflict of Interest: The authors declare that the research was conducted in the absence of any commercial or financial relationships that could be construed as a potential conflict of interest.

Publisher's Note: All claims expressed in this article are solely those of the authors and do not necessarily represent those of their affiliated organizations, or those of the publisher, the editors and the reviewers. Any product that may be evaluated in this article, or claim that may be made by its manufacturer, is not guaranteed or endorsed by the publisher.

Copyright (c) 2021 Weinberg, Seyd, Gaskell, Hamm and Zmerli. This is an openaccess article distributed under the terms of the Creative Commons Attribution License (CC BY). The use, distribution or reproduction in other forums is permitted, provided the original author(s) and the copyright owner(s) are credited and that the original publication in this journal is cited, in accordance with accepted academic practice. No use, distribution or reproduction is permitted which does not comply with these terms. 